\title{
A chondroitin sulfate proteoglycan 4-specific monoclonal antibody inhibits melanoma cell invasion in a spheroid model
}

\author{
KAROLINA URANOWSKA ${ }^{1,2}$, MAHZEIAR SAMADAEI ${ }^{3}$, TANJA KALIC ${ }^{1,2}$, \\ MATTHIAS PINTER ${ }^{3}$, HEIMO BREITENEDER ${ }^{2}$ and CHRISTINE HAFNER ${ }^{1,4}$
}

\author{
${ }^{1}$ Department of Dermatology, University Hospital St. Poelten, Karl Landsteiner University of Health Sciences, \\ A-3100 St. Poelten; ${ }^{2}$ Institute of Pathophysiology and Allergy Research, Center for Pathophysiology, \\ Infectiology and Immunology, Medical University of Vienna; ${ }^{3}$ Department of Internal Medicine III, \\ Division of Gastroenterology and Hepatology, Medical University of Vienna, A-1090 Vienna; \\ ${ }^{4}$ Karl Landsteiner Institute of Dermatological Research, Karl Landsteiner Gesellschaft, A-3100 St. Poelten, Austria
}

Received May 14, 2021; Accepted July 12, 2021

DOI: $10.3892 / \mathrm{ijo} .2021 .5250$

\begin{abstract}
The overexpression of chondroitin sulfate proteoglycan 4 (CSPG4) is associated with several tumor types, including malignant melanoma, squamous cell carcinoma, triple-negative breast carcinoma, oligodendrocytomas or gliomas. Due to its restricted distribution in normal tissues, CSPG4 has been considered a potential target for several antitumor approaches, including monoclonal antibody $(\mathrm{mAb})$ therapies. The aim of the present study was to characterize the impact of the CSPG4-specific mAb clone 9.2.27 on its own or in combination with the commonly used BRAF-selective inhibitor, PLX4032, on different functions of melanoma cells to assess the potential synergistic effects. The BRAF V600-mutant human melanoma cell lines, M14 (CSPG4-negative) and WM164 (CSPG4-positive), were exposed to the CSPG4-specific 9.2.27 mAb and/or PLX4032. Cell viability and colony formation capacity were evaluated. A 3D-cell culture spheroid model was used to assess the invasive properties of the treated cells. In addition, flow cytometric analysis of apoptosis and cell cycle analyses were performed.
\end{abstract}

Correspondence to: $\mathrm{Dr}$ Christine Hafner, Department of Dermatology, University Hospital St. Poelten, Karl Landsteiner University of Health Sciences, Dunant-Platz 1, A-3100 St. Poelten, Austria

E-mail: christine.hafner@edu.kl.ac.at

Abbreviations: CSPG4, chondroitin sulfate proteoglycan 4; ECM, extracellular matrix; ERK, extracellular signal-regulated kinase; FAK, focal adhesion kinase; mAb, monoclonal antibody; MAPK, mitogen-activated protein kinase; MEK, mitogen-activated protein kinase kinase; PBS, phosphate-buffered saline; RTK, receptor tyrosine kinase

Key words: melanoma, CSPG4, monoclonal antibody, BRAF-mutated melanoma, BRAF inhibitor, CSPG4-positive tumors, CSPG4-specific antibody, cell invasion inhibition, spheroids
Incubation of the WM164 cell line with CSPG4-specific 9.2.27 mAb decreased viability, colony formation ability and the invasive capacity of CSPG4-positive tumor cells, which was not the case for the CSPG4-negative M14 cell line. Combined treatment of the WM164 cells with 9.2.27 mAb plus PLX4032 did not exert any significant additional effect in comparison to treatment with PLX4032 alone in the clonogenic and invasion assays. M14 cell cycle distribution was not influenced by the CSPG4-specific 9.2.27 mAb. By contrast, the exposure of WM164 cells to the mAb resulted in an arrest of the cells in the S phase. Moreover, combined treatment of the WM164 cells led to a significantly increased accumulation of cells in the subG1 phase, combined with a decrease of cells in the G2/M phase. On the whole, findings of the present study indicate that the CSPG4-specific 9.2.27 mAb exerts an anti-invasive effect on CSPG4-positive melanoma spheroids, which is not enhanced by BRAF inhibition. These findings provide the basis for further investigations on the effects of anti-CSPG4-based treatments of CSPG4-positive tumors.

\section{Introduction}

Chondroitin sulfate proteoglycan 4 (CSPG4), also known as high molecular weight-melanoma associated antigen (HMW-MAA) or melanoma chondroitin sulfate proteoglycan (MCSP) was first characterized on human melanoma cells 40 years ago (1). CSPG4 is a single-pass type I transmembrane protein expressed either as an $280-\mathrm{kDa} \mathrm{N}$-linked glycoprotein or as a 450-kDa chondroitin sulfate proteoglycan (2). Although CSPG4 was originally associated only with melanoma progression due to its widespread expression in the majority $(\geq 70 \%)$ of these tumors (3), it was later also detected in other hematological and solid neoplastic conditions, including several types of leukemia (4), head and neck squamous-cell carcinomas (5), triple-negative breast carcinoma (TNBC) (6), gliomas (7), pancreatic tumors (8), soft-tissue sarcomas (9) and malignant mesothelioma (10). As a transmembrane proteoglycan, CSPG4 functions as a key mediator molecule connecting the extracellular matrix (ECM) with intracellular binding partners (11). 
CSPG4 thus activates major signaling pathways involved in melanoma cell survival, proliferation, migration and invasion, in particular via the integrin-regulated focal adhesion kinase (FAK) pathway and receptor tyrosine kinase (RTK)-mediated mitogen-activated protein kinase (MAPK) cascade (11-13).

Due to its ability to influence different functions of tumor cells and to its restricted distribution in adult healthy tissues, CSPG4 is perceived as an attractive target for anti-tumor immunotherapy $(13,14)$. To date, only a limited number of anti-CSPG4 monoclonal antibodies (mAbs) targeting CSPG4-positive tumors has been described, including 9.2.27 mAb, 225.28 mAb and TP41.2 mAb (6,10,15).

The highly specific $\mathrm{mAb}$ 9.2.27 directed against the core glycoprotein of the chondroitin sulfate proteoglycan has been widely used for immunodiagnostic imaging of CSPG4 and as a basis for immunotherapy. The majority of research on therapeutic approaches involved CSPG4-specific 9.2.27 mAb coupled to a variety of cell death-inducing agents (16). One interesting concept based on the $\alpha$-particle-emitting radioisotope ${ }^{213}$ bismuth conjugated to the mAb $\left({ }^{213} \mathrm{Bi}-9.2 .27\right)$ was found to be highly specific and cytotoxic to melanoma cells (17). Another treatment strategy involved a chemical conjugate of 9.2.27 mAb with the pseudomonas exotoxin $\mathrm{A}(\mathrm{PE})$, resulting in the melanoma-specific 9.2.27PE immunotoxin that efficiently killed cells in vitro (18). A different approach was based on the TNF-related apoptosis-inducing ligand (TRAIL) conjugated to an anti-CSPG4 scFv based on the mAb 9.2.27. Treatment with this anti-MCSP:TRAIL construct resulted in apoptotic melanoma cell death in vitro and exerted no off-target effects on normal melanocytes (19). In addition, it caused a significant growth retardation of human melanoma xenografts.

Apart from malignant melanoma, the 9.2.27 mAb was employed to inhibit the growth of other CSPG4-positive tumor types, including soft-tissue sarcoma (9), triple-negative breast carcinoma as a 9.2.27 mAb-based cytolytic fusion protein $(\alpha \mathrm{CSPG} 4(\mathrm{scFv})-\mathrm{MAP})$ with pro-apoptotic activity (20) and glioblastoma multiforme as a PEGylated mAb used in combination with adoptive natural killer (NK) cell transfer (21).

Over the years, the use of BRAF inhibitors (BRAFi) has become a valid anti-melanoma therapeutic strategy for patients with confirmed BRAF mutations $(22,23)$. However, even when combined with a mitogen-activated protein kinase kinase (MEK) inhibitor, these treatment modalities rarely lead to a complete clinical response due to intrinsic or acquired resistance (24). Thus, additional treatment options or alternative treatment combinations with the potential to overcome resistance are required for the better management of patients with metastatic melanoma.

Yu et al (25) indicated that the addition of the anti-CSPG4 $225.28 \mathrm{mAb}$ to treatment with the BRAF inhibitor, PLX4032, enhanced the response magnitude and the duration of PLX4032 efficacy in CSPG4-positive melanoma cells. In addition, it was previously revealed that CSPG4-specific polyclonal antibodies enhanced the anti-proliferative effects of PLX4032 in melanoma cell lines (26). However, the beneficial effect of this combinational treatment was partially blocked under hypoxic conditions (26).

On the ground of a number of promising studies employing the CSPG4-specific 9.2.27 $\mathrm{mAb}$, the authors wished to determine whether it could synergize with the potent BRAF inhibitor, PLX4032, in constraining various melanoma cellular functions. Thus, the present study, validated the antitumor efficacy of each agent individually, as well as the effects of a combined treatment that may lead to better results than each agent alone.

The present study investigated the behavior of melanoma cells following treatments not only in two-dimensional cell culture assays, but also in a more physiologically relevant system utilizing 3D tumor spheroids. Spheroids are scaffold-free spherical self-assembled aggregates of cancer cells (27). In living organisms, cells are organized in 3D microenvironments with complex cell-cell and cell-matrix interactions and intricate transport dynamics. Therefore, 3D tumor spheroids better resemble a living tissue with respect to the cellular communication and the development of an extracellular matrix (28). Moreover, 3D cell cultures provide more correct cell polarization, since the cells in monolayers can be only partially polarized (29). In addition, this type of three-dimensional cell culture system has contributed to reduce the use of laboratory animal models (27). Melanoma spheroids have been proven to be a very useful model for studying novel therapeutics and their anti-invasive and anti-metastatic effects (30-34). Such models are utilized in cancer research as a more accurate representation of the in vivo tumor microenvironment as compared to traditional two-dimensional (2D) cell culture. A melanoma spheroid model is able to mimic the effects of cell-cell interactions, hypoxia and nutrient deprivation, and drug penetration. 3D tumor spheroids have been established as tumor models for a number of years; however, over the past decade, they have come into more common usage as an in vitro model for solid tumors, e.g., melanoma (33). These models are increasingly being used in high-throughput drug discovery screens as an intermediate between complex, expensive and time-consuming in vivo models and the simple, low cost 2D monolayer model (30).

In the present study, it was demonstrated that the exposure of the CSPG4-positive WM164 melanoma cell line to the CSPG4-specific 9.2.27 mAb decreased viability, colony formation ability and invasion, which was not the case for the CSPG4-negative cell line, M14. Notably, the 9.2.27 mAb contributed to an additional inhibition of WM164 cell viability, as compared with the use of PLX4032 alone. By contrast, combined treatment of the WM164 cells with 9.2.27 mAb and PLX4032 did not exert any significant additional effect in clonogenic and invasion assays. Cell cycle arrest in the $S$ phase was observed upon exposure to the antibody. These findings provide the basis for further investigation of CSPG4-antibodies for the treatment of CSPG4-positive tumors.

\section{Materials and methods}

Cell lines and reagents. The human CSPG4-positive melanoma cell lines, WM9, WM35, WM164, 451Lu, and the human CSPG4-negative melanoma cell line, M14, all harboring the BRAF V600E mutation, were previously described $(35,36)$. The cells were maintained in RPMI-1640 medium with $2 \mathrm{mM}$ L-glutamine and $25 \mathrm{mM}$ Hepes (Lonza Group, Ltd.), supplemented with either 5\% FBS (WM9, WM35, WM164 and $451 \mathrm{Lu}$ ) or $10 \%$ FBS (M14) and $1 \%$ penicillin-streptomycin (Gibco; Thermo Fisher Scientific, Inc.). Cells were cultured in 
a humidified atmosphere containing $5 \% \mathrm{CO}_{2}$ and $95 \%$ ambient air at $37^{\circ} \mathrm{C}$. Prior to the experiments, all cell lines tested negative for mycoplasma. PLX4032, a potent inhibitor of mutant BRAF V600, was purchased from Selleck Chemicals. The mouse mAb clone 9.2.27 recognizing CSPG4 (\#CUST04896) was obtained from eBioscience ${ }^{\mathrm{TM}}$ (Thermo Fisher Scientific, Inc.). Control mouse IgG (\#I5381) was obtained from Sigma-Aldrich; Merck KGaA.

MTT assay. To investigate cell viability upon exposure to increasing concentrations of PLX4032 and CSPG4-specific 9.2.27 mAb, a CytoSelect ${ }^{\mathrm{TM}}$ MTT Cell Proliferation assay (Cell Biolabs, Inc.) was performed according to the manufacturer's instructions. Briefly, the melanoma cells were seeded in triplicates at a density of 6,000 cells per well in 96-well plates and subjected to the following treatments for 24 and $72 \mathrm{~h}$. The concentrations used for the experiments were as follows: PLX4032 at 0, 0.01,0.1 and 0.25 $\mu \mathrm{M}$; anti-CSPG4 9.2.27 mAb or IgG control at $0,0.2,2,5$ and $10 \mu \mathrm{g} / \mathrm{ml}$ and their combinations thereof. The cells were then incubated with MTT reagent for $3 \mathrm{~h}$ at $37^{\circ} \mathrm{C}$ and solubilized. The absorbance was measured at 540 and $570 \mathrm{~nm}$ using a Spark ${ }^{\circledR}$ multimode microplate reader (Tecan Group Ltd.). The presented data are the results of three independent experiments performed in triplicate and are shown as percentage of viable cells, compared with the untreated control cells.

Flow cytometry. Melanoma cells were harvested by scraping, washed with 1X PBS and dispensed into FACS tubes. The cells were then incubated with Fixable Viability Dye eFluor ${ }^{\circledR}$ 506 (Affymetrix; Thermo Fisher Scientific, Inc.) for $30 \mathrm{~min}$ at $4^{\circ} \mathrm{C}$ in dark according to the manufacturer's protocol. The cells were then washed with FACS buffer $(0.5 \%$ BSA and $0.05 \%$ sodium azide $\left(\mathrm{NaN}_{3}\right)$ in $1 \mathrm{X}$ PBS $)$ and incubated with anti-CSPG4 antibody 9.2.27 (1:1,000; cat. no. 554275; BD Pharmingen; BD Biosciences) for $10 \mathrm{~min}$ at $4^{\circ} \mathrm{C}$, washed with FACS buffer and incubated with donkey anti-mouse secondary IgG antibodies Alexa Fluor $488^{\circledR}$ (1:500) for $15 \mathrm{~min}$ at $4^{\circ} \mathrm{C}$, protected from light. As a control for the $\mathrm{IgG}$ antibodies, cells were incubated with the Alexa Fluor $488^{\circledR}$ secondary antibody (1:500; cat. no. A-21202, Thermo Fisher Scientific, Inc.) only also for $15 \mathrm{~min}$ at $4^{\circ} \mathrm{C}$, protected from light. The cells were washed and resuspended in FACS buffer. The samples were analyzed using a FACSCanto flow cytometer (BD Biosciences). FlowJo software version 10.6.1 (TreeStar Inc.) was used for the analysis of the results.

Colony formation assay. Melanoma cells were seeded in duplicates into 6-well plates at a density of 1,000 cells per well and subjected to the following treatments: PLX4032 $(0.1 \mu \mathrm{M})$, 9.2.27 mAb $(2 \mu \mathrm{g} / \mathrm{ml})$, PLX4032 $(0.1 \mu \mathrm{M})$ plus 9.2.27 mAb $(2 \mu \mathrm{g} / \mathrm{ml}), \mathrm{IgG}$ control $(2 \mu \mathrm{g} / \mathrm{ml})$, PLX4032 $(0.1 \mu \mathrm{M})$ plus IgG control $(2 \mu \mathrm{g} / \mathrm{ml})$. Untreated cells served as a control. The cells were incubated until they formed colonies at approximately after 12 days for the M14 cell line and 16 days for the WM164 cell line. The cells were then washed with PBS, fixed with $4 \%$ paraformaldehyde solution in PBS for $30 \mathrm{~min}$ at room temperature and stained using crystal violet solution $(0.2 \%$ crystal violet and $2 \%$ ethanol in $\mathrm{ddH}_{2} \mathrm{O}$ ) for $30 \mathrm{~min}$ at room temperature. The number of colonies including $>50$ cells was quantified using the ImageJ software version 1.53 (National Institutes of Health). The presented data are the results of three independent experiments performed in duplicate.

Spheroid invasion assay. For creating spheroids, the hanging drop method was used. The WM164 and M14 melanoma cells untreated or exposed to specific treatments were harvested by scraping and resuspended in culture medium containing $0.3 \%$ methylcellulose. Drops of $30 \mu 1$ of the suspension ( 1,000 cells) were distributed equally over a $10-\mathrm{cm}$ dish. The plates were incubated upside down for 2 days at $37^{\circ} \mathrm{C}$ to allow the formation of stable spheroids. The hanging drops were then collected into a $50 \mathrm{ml}$ falcon tube and embedded into $1.5 \%$ rat tail collagen gels (Corning ${ }^{\mathrm{TM}}$ 354236, Merck KGaA). To prepare collagen gels, a $3 \%$ collagen solution was mixed with an equal volume of $0.85 \%(\mathrm{w} / \mathrm{v})$ methylcellulose with RPMI-1640 culture medium supplemented with either 5\% FBS (WM164) or $10 \%$ FBS (M14). The spheroid suspension was pipetted into 24 -well plates $(350 \mu \mathrm{l} /$ well) and placed into an incubator for $30 \mathrm{~min}$ at $37^{\circ} \mathrm{C}$ for polymerization. For stimulation, collagen gels were overlaid with medium containing $0.5 \% \mathrm{FBS}$ and then incubated at $37^{\circ} \mathrm{C}$. The quantification of sprouting intensity after $24 \mathrm{~h}$ of incubation was determined using a Nikon inverted phase-contrast microscope. The area of spheroids was measured using ImageJ software version 1.53 (National Institutes of Health). For each treatment 3 spheroids were quantified. The presented data are the results of three independent experiments performed in triplicates.

Apoptosis assay. The Annexin V-CF Blue/7-AAD Apoptosis Detection kit (Abcam) was used to estimate the percentage of intact (Annexin', 7-AAD'), apoptotic (Annexin', 7-AAD') or necrotic (Annexin ${ }^{+}, 7-\mathrm{AAD}^{+}$) cells following $72 \mathrm{~h}$ of treatments. The analysis was performed according to the manufacturer's instructions. In brief, cells were seeded in triplicate in six-well plates and subjected to the following treatments: PLX4032 $(0.1 \mu \mathrm{M}), 9.2 .27 \mathrm{mAb}$ or IgG control $(2 \mu \mathrm{g} / \mathrm{ml})$ and PLX4032 $(0.1 \mu \mathrm{M})$ plus $9.2 .27 \mathrm{mAb}(2 \mu \mathrm{g} / \mathrm{ml})$ or IgG control $(2 \mu \mathrm{g} / \mathrm{ml})$. Untreated cells served as a control. The cells were then harvested, washed with PBS and resuspended in Annexin-binding buffer. The cells were then incubated in the dark with Annexin V-CF Blue Conjugate and 7-AAD Staining Solution for $15 \mathrm{~min}$ at room temperature. The samples were analyzed using a FACSCanto flow cytometer (BD Biosciences). FlowJo software version 10.6.1 (TreeStar Inc.) was used for the analysis of the results. The presented data are the results of three independent experiments performed in triplicate.

Cell cycle analysis. The analysis of the cell cycle was performed using a Propidium Iodide Flow Cytometry kit (Abcam) according to the manufacturer's protocol. Briefly, melanoma cells were seeded in triplicate in six-well plates and exposed to the following treatments: PLX4032 $(0.1 \mu \mathrm{M})$, 9.2.27 mAb $(2 \mu \mathrm{g} / \mathrm{ml}), \operatorname{PLX} 4032(0.1 \mu \mathrm{M})$ plus 9.2.27 $\mathrm{mAb}$ $(2 \mu \mathrm{g} / \mathrm{ml}), \mathrm{IgG}$ control $(2 \mu \mathrm{g} / \mathrm{ml})$, PLX4032 $(0.1 \mu \mathrm{M})$ plus IgG control $(2 \mu \mathrm{g} / \mathrm{ml})$ for $72 \mathrm{~h}$. Untreated cells served as a control. The cells were then harvested in a single cell suspension and fixed with $66 \%$ ethanol for at least $2 \mathrm{~h}$, at $4^{\circ} \mathrm{C}$. The cells were then washed with PBS and resuspended in $1 \mathrm{X}$ propidium iodide + RNase staining solution. Following incubation for 
A

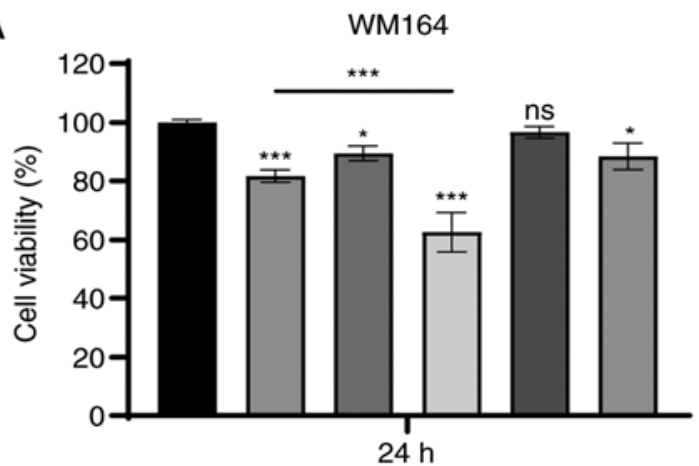

B

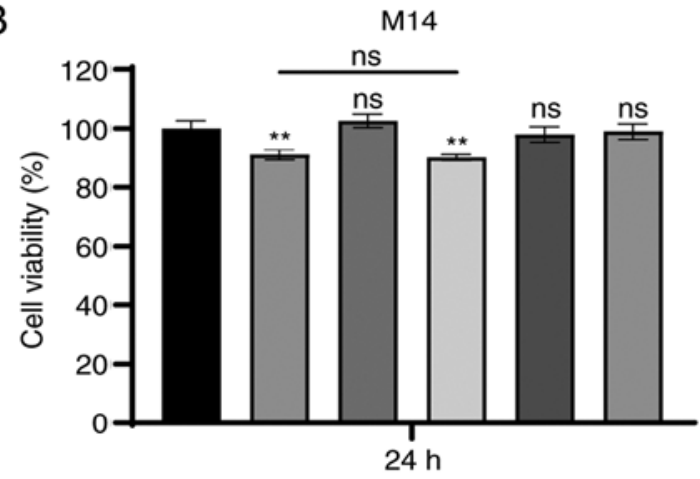

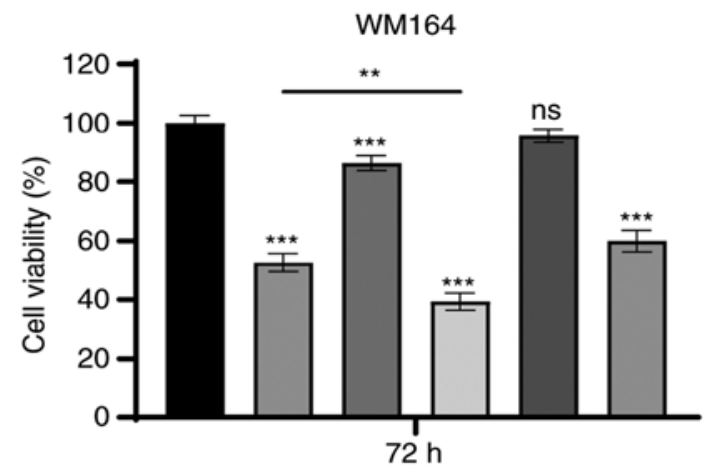

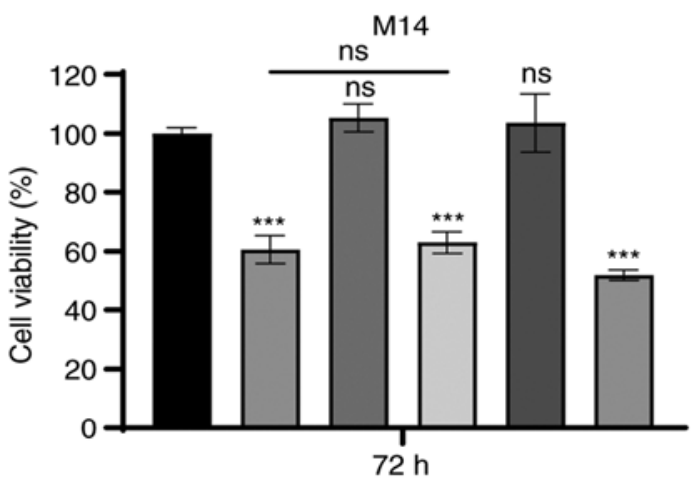

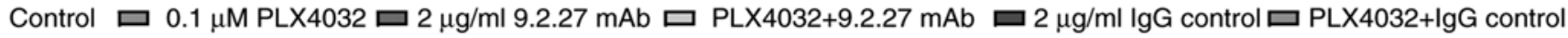

Figure 1. Viability of melanoma cells following treatment with PLX4032, CSPG4-specific 9.2.27 mAb and the combination thereof. (A) Viability of CSPG4-positive WM164 cells and (B) viability of CSPG4-negative M14 cells following exposure of the cells to the treatments [PLX4032 (0.1 $\mu$ M), 9.2.27 mAb $(2 \mu \mathrm{g} / \mathrm{ml})$, PLX4032 $(0.1 \mu \mathrm{M})$ plus $9.2 .27 \mathrm{mAb}(2 \mu \mathrm{g} / \mathrm{ml})$, IgG control $(2 \mu \mathrm{g} / \mathrm{ml})$, PLX4032 $(0.1 \mu \mathrm{M}) \mathrm{plus}$ IgG control $(2 \mu \mathrm{g} / \mathrm{ml})] \mathrm{was} \mathrm{measured} \mathrm{using} \mathrm{MTT}$ assay after $24 \mathrm{~h}$ (left panels) and $72 \mathrm{~h}$ (right panels). The results are presented as the percentage of viable cells, compared with the untreated cells (control) and represent three independent experiments performed in triplicate. Bars represent the mean \pm SD. Statistical analysis was carried out using one-way ANOVA with Tukey's multiple comparisons test. P-values are represented by asterisks $\left({ }^{*}\right)$ : ${ }^{* * *} \mathrm{P}<0.0001,{ }^{* *} \mathrm{P}<0.01,{ }^{*} \mathrm{P}<0.05 ;$ ns, not significant. Asterisks above each bar indicate significance, as compared with the control bar. Line with depicted asterisks above different bars indicates significance between relevant bars. CSPG4, chondroitin sulfate proteoglycan $4 ; \mathrm{mAb}$, monoclonal antibody.

$30 \mathrm{~min}$ at $37^{\circ} \mathrm{C}$, the cells were analyzed for cell cycle distribution with a FACSCanto flow cytometer (BD Biosciences). FlowJo software version 10.6.1 (TreeStar Inc.) was used for the analysis of the results. The presented data are the results of three independent experiments performed in triplicate.

Statistical analysis. The statistical analysis of differences between treated groups was performed using one-way ANOVA with Tukey's multiple comparisons test. P-values $<0.05$ were considered to indicate statistically significant differences. All statistical analyses of the experiments were carried out using GraphPad Prism software version 4.03 and 9.01.151 (GraphPad Software, Inc.).

\section{Results}

Effects of CSPG4-specific 9.2.27 mAb and PLX4032 alone or in combination on melanoma cell viability. The present study first verified the effects of the potent BRAF V600 inhibitor, PLX4032, as well as those of the CSPG4-specific 9.2.27 $\mathrm{mAb}$, and the combination of both on the viability of melanoma cell lines. To determine the most appropriate concentrations for treatments, dose-titration experiments were performed (Fig. S1). The concentration of $0.1 \mu \mathrm{M}$ PLX4032 was selected for the study as it inhibited $\sim 50 \%$ of the viability of the WM164 and M14 cells (Fig. S1). For the CSPG4-specific 9.2.27 $\mathrm{mAb}$, the lowest concentration of the $\mathrm{mAb}(2 \mu \mathrm{g} / \mathrm{ml})$ which exerted a statistically significant effect on the viability of CSPG4-positive WM164 cells alone and in combination with $0.1 \mu \mathrm{M}$ PLX4032 was selected (Fig. S1A).

Exposure of the cells to PLX4032 resulted in a decreased cell viability of CSPG4-negative M14 and CSPG4-positive WM164 cells, as compared with the untreated cells (Fig. 1). The viability of the PLX4032-exposed WM164 cells decreased by $18.3 \pm 1.7 \%$ following incubation for $24 \mathrm{~h}$ and by $47.3 \pm 2.6 \%$ after $72 \mathrm{~h}$ (Fig. 1A). The viability of the M14 cells exposed to PLX4032 decreased by $9 \pm 1.4 \%$ and by $39.3 \pm 3.9 \%$ following 24 and $72 \mathrm{~h}$ of incubation, respectively (Fig. 1B). The exposure of the WM164 cell line to the CSPG4-specific 9.2.27 mAb significantly decreased cell viability, which was not the case for the CSPG4-negative M14 cell line (Fig. 1A and B). The specificity of the effect of the 9.2.27 mAb was repeated in four CSPG4-high expressing melanoma cells (Fig. S2). The IgG control antibody had no detectable effect on both WM164 and M14 cell lines (Fig. 1A and 1B). When combined with PLX4032, the anti-CSPG4 mAb contributed to a significant, additional inhibition of WM164 cell viability, as compared with the cells treated with BRAF inhibitor alone, decreasing the viability by $37.3 \pm 5.4 \%$ after $24 \mathrm{~h}$ and by $60.7 \pm 2.4 \%$ after $72 \mathrm{~h}$ (Fig. 1A). This decreased viability 
A
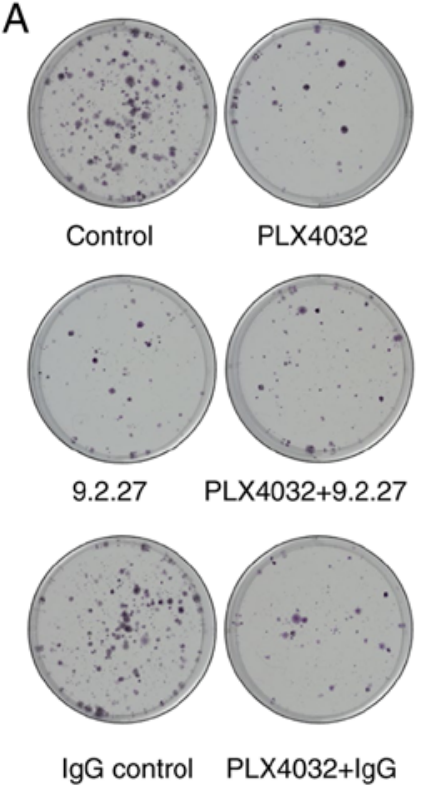

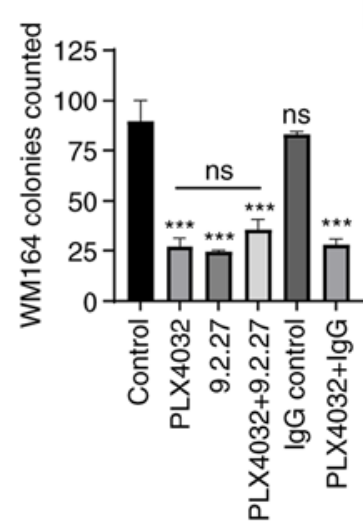

B
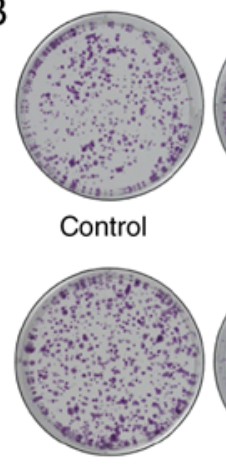

9.2 .27

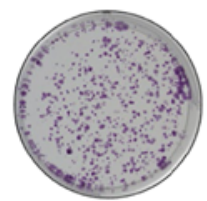

IgG control

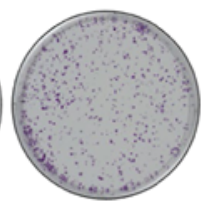

PLX4032

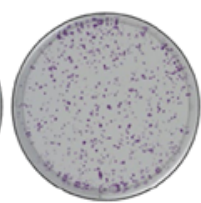

PLX4032+9.2.27

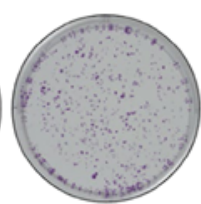

PLX4032+lgG

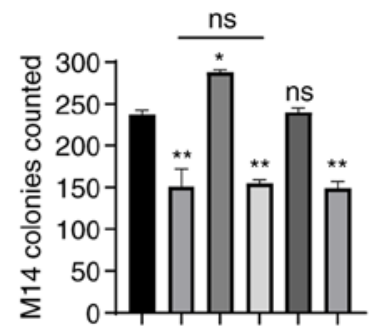

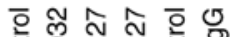

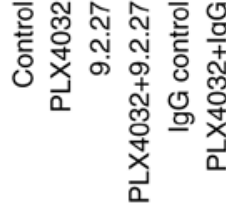

Figure 2. The CSPG4-specific 9.2.27 mAb exerts a similar effect as PLX4032 on the colony-forming ability of CSPG4-positive melanoma cells. (A) Representative images of fixed and stained WM164 colonies and (B) M14 colonies under different conditions (left panels) after 16 and 12 days of treatment, respectively. The number of colonies from three independent experiments was counted and presented on the bar graphs (right panels). Bars represent the mean \pm SD from duplicate experiments. Statistical analysis was carried out using one-way ANOVA with Tukey's multiple comparisons test. P-values are represented by asterisks $(*):{ }^{* * *} \mathrm{P}<0.001,{ }^{* *} \mathrm{P}<0.01$; ns, not significant. Asterisks above each bar indicate significance, as compared to the control bar. Line with depicted asterisks above different bars indicates significance between relevant bars. CSPG4, chondroitin sulfate proteoglycan 4 ; mAb, monoclonal antibody.

was indeed CSPG4-dependent since the combined treatment of CSPG4-negative M14 cells with PLX4032 plus 9.2.27 mAb did not exert any additional effect, as compared to treatment with PLX4032 alone (Fig. 1B). The combination of PLX4032 with the IgG control resulted in the same effect as PLX4032 for both cell lines tested (Fig. 1A and B).

In addition, the present study evaluated using bright-field microscopy, whether changes in cell viability following the treatments were reflected in differences in the density and morphology of the melanoma cells. Indeed, as illustrated in the representative images, PLX4032 decreased the number of both WM164 and M14 cells and it affected cell morphology, as compared with the control (Fig. S3). Exposure to the 9.2.27 $\mathrm{mAb}$ for $72 \mathrm{~h}$ resulted in a decreased density of CSPG4-positive WM164 cells, whereas it had no effect on CSPG4-negative M14 cells.

Taken together, the results of MTT assay proved that the exposure to PLX4032 efficiently inhibited the viability of BRAF V600E-mutant cell lines. Moreover, the anti-CSPG4 mAb specifically decreased the viability of only CSPG4-positive cells and enhanced the effects of PLX4032. The specific effect on cell viability was observed at even after $24 \mathrm{~h}$ and continued after $72 \mathrm{~h}$. Therefore, these incubation times were used in the present study.

CSPG4-specific 9.2.27 mAb exerts similar effect as PLX4032 on the colony-forming ability of CSPG4-positive melanoma cells. After demonstrating that the viability of both WM164 and M14 cells was reduced following exposure to PLX4032, and that only CSPG4-positive cells were influenced by incubation with 9.2.27 mAb, the present study investigated whether these treatment regimens had an effect on the colony-forming ability of melanoma cells. For this purpose, cells were plated as single cells and subjected to treatments as described in the Materials and methods section for the time period required for cells to form colonies (12 days for the M14 cell line and 16 days for the WM164 cell line). The M14 cells exhibited a significantly reduced ability to form colonies when exposed to PLX4032 (average of $236.5 \pm 4.5$ colonies in untreated cell line versus $149.5 \pm 16.5$ colonies after BRAFi), while no inhibitory effect of the CSPG4-specific mAb was observed (Fig. 2B). Furthermore, the combination of BRAF inhibitor with the $\mathrm{mAb}$ resulted in the same effect as that observed with PLX4032 alone (Fig. 2B).

The colony-forming inhibitory effect of PLX4032 was also observed in the WM164 cells (Fig. 2A). These CSPG4-expressing cells exhibited a significantly reduced ability to form colonies also when incubated with CSPG4-specific 9.2.27 mAb (Fig. 2A). Both treatments separately reduced the number of colonies by $\sim 70 \%$. The combination of PLX4032 with the 9.2.27 $\mathrm{mAb}$ did not exert any additional inhibitory effect on colony formation, as compared with either agent alone (Fig. 2A).

In summary, incubation with the 9.2.27 mAb exerted a similar inhibitory effect on the colony-forming ability of CSPG4-positive melanoma cells as that observed with PLX4032 alone. It also did not contribute to an additional decrease in the number of colonies when used in combination with the BRAF inhibitor.

CSPG4-specific 9.2.27 $m A b$ decreases the invasion of CSPG4-positive melanoma cells. CSPG4 is a multifunctional transmembrane proteoglycan involved in the induction of melanoma cell invasion (3). Hence, in the following experiment, the present study investigated whether the CSPG4-specfic 9.2.27 mAb alone or in combination with PLX4032 exerts an 

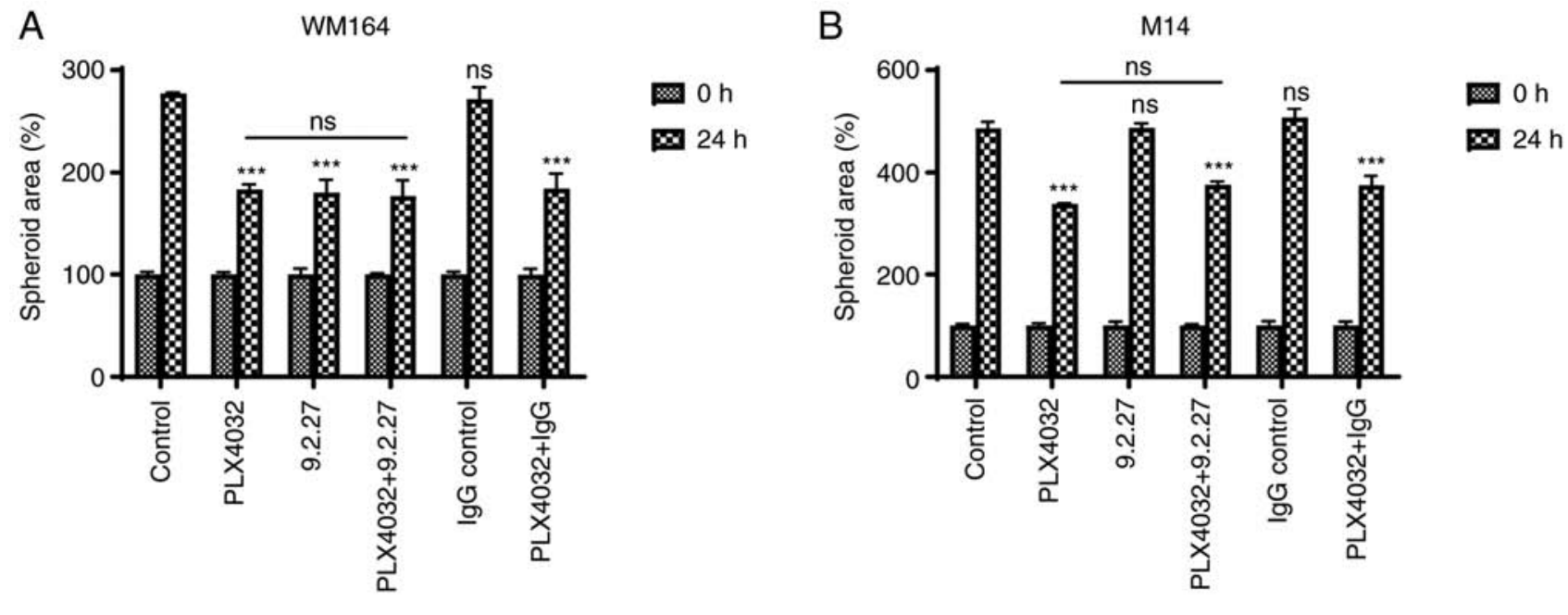

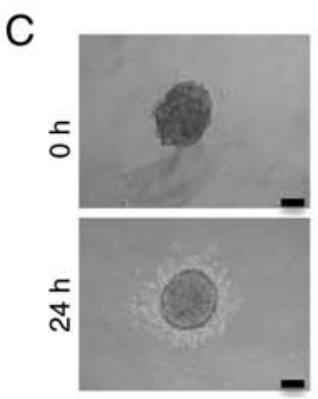

Control

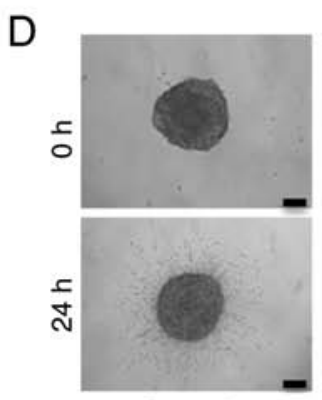

Control

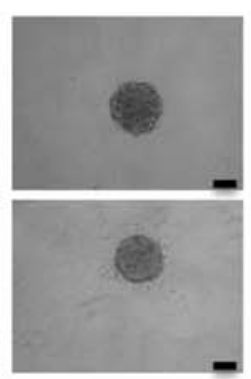

PLX4032

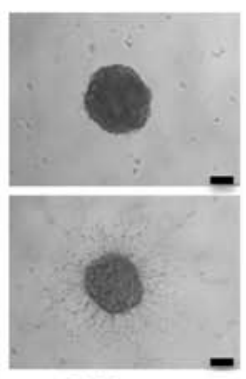

PLX4032

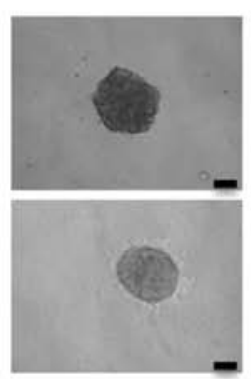

9.2.27

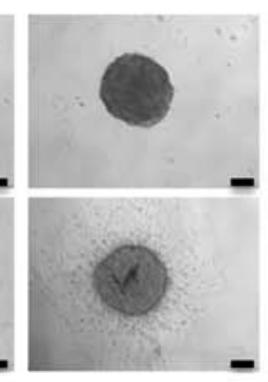

9.2.27

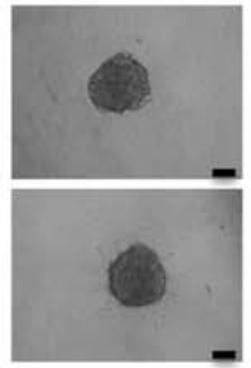

PLX4032+9.2.27

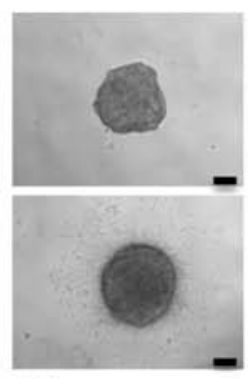

PLX4032+9.2.27

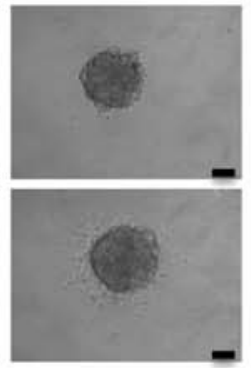

IgG control

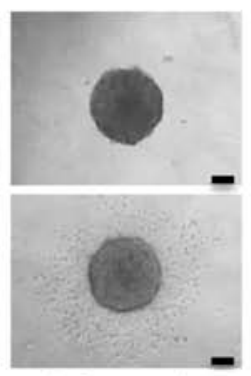

IgG control

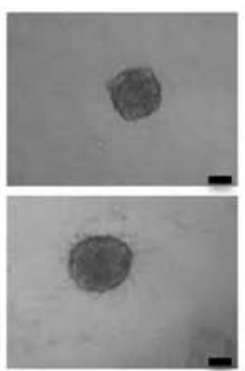

PLX4032+lgG

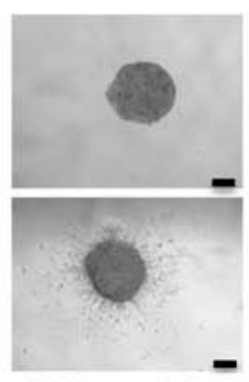

PLX4032+lgG

Figure 3. The CSPG4-specific 9.2.27 mAb decreases the invasion of CSPG4-positive melanoma cells. (A) The area of WM164 spheroids and (B) M14 spheroids exposed to different treatments was measured at 0 and $24 \mathrm{~h}$ after embedding in a collagen matrix. The results are presented as a percentage of spheroid area, calculated by comparing the spheroid area after $24 \mathrm{~h}$ to spheroids at the initial time $0 \mathrm{~h}$. Bars represent the mean \pm SD from triplicates of three independent experiments. Statistical analysis was carried out using one-way ANOVA with Tukey's multiple comparisons test. P-values are represented by asterisks $(*)$ : ${ }^{* * *} \mathrm{P}<0.001$; ns, not significant. Asterisks above each bar indicate significance, as compared to the control bar. Line with depicted asterisks above different bars indicates significance between relevant bars. (C and D) A series of representative micrographs showing a spheroid growth and invasion under different treatments at 0 and after $24 \mathrm{~h}$. Images of (C) CSPG4-positive WM164 spheroids and (D) CSPG4-negative M14 spheroids. Scale bar, 100 $\mu$ m. CSPG4, chondroitin sulfate proteoglycan 4 ; mAb, monoclonal antibody.

effect on melanoma cell invasion in a 3D spheroid model. The ability to form stable spheroids has been previously reported for WM164 cells (33).

WM164 (CSPG4-positive) and M14 (CSPG4-negative) cell-derived spheroids were exposed to different treatments and their ability to invade into a collagen matrix was evaluated. In line with the results of MTT assay, specific effects were observed even after $24 \mathrm{~h}$. Both the WM164 and M14 cell-derived spheroids exposed to the BRAF inhibitor exhibited a significantly reduced invasive ability as compared with the control (Fig. 3A and B). The size of the PLX4032-exposed spheroids, as well as the area of invaded cells in both cell lines was markedly smaller, when compared with the control spheroids (Fig. 3C and D). Incubation of WM164 spheroids with the CSPG4-specific 9.2.27 mAb significantly inhibited the invasion of CSPG4-positive tumor cells (Fig. 3A). The specificity of the effect of the 9.2.27 mAb was again confirmed by the observation that the antibodies did not influence the invasion of CSPG4-negative cells (Fig. 3B and D). The area of invading cells was distinctly reduced in the mAb-treated WM164 cell-derived spheroids, as compared with the untreated or IgG control-treated spheroids (Fig. 3C). Notably, consistent with the results of the colony formation assay, the combination of PLX4032 with the 9.2.27 mAb did not exert any additional effect, as compared with the influence of each agent alone on spheroids (Fig. 3A and C). 

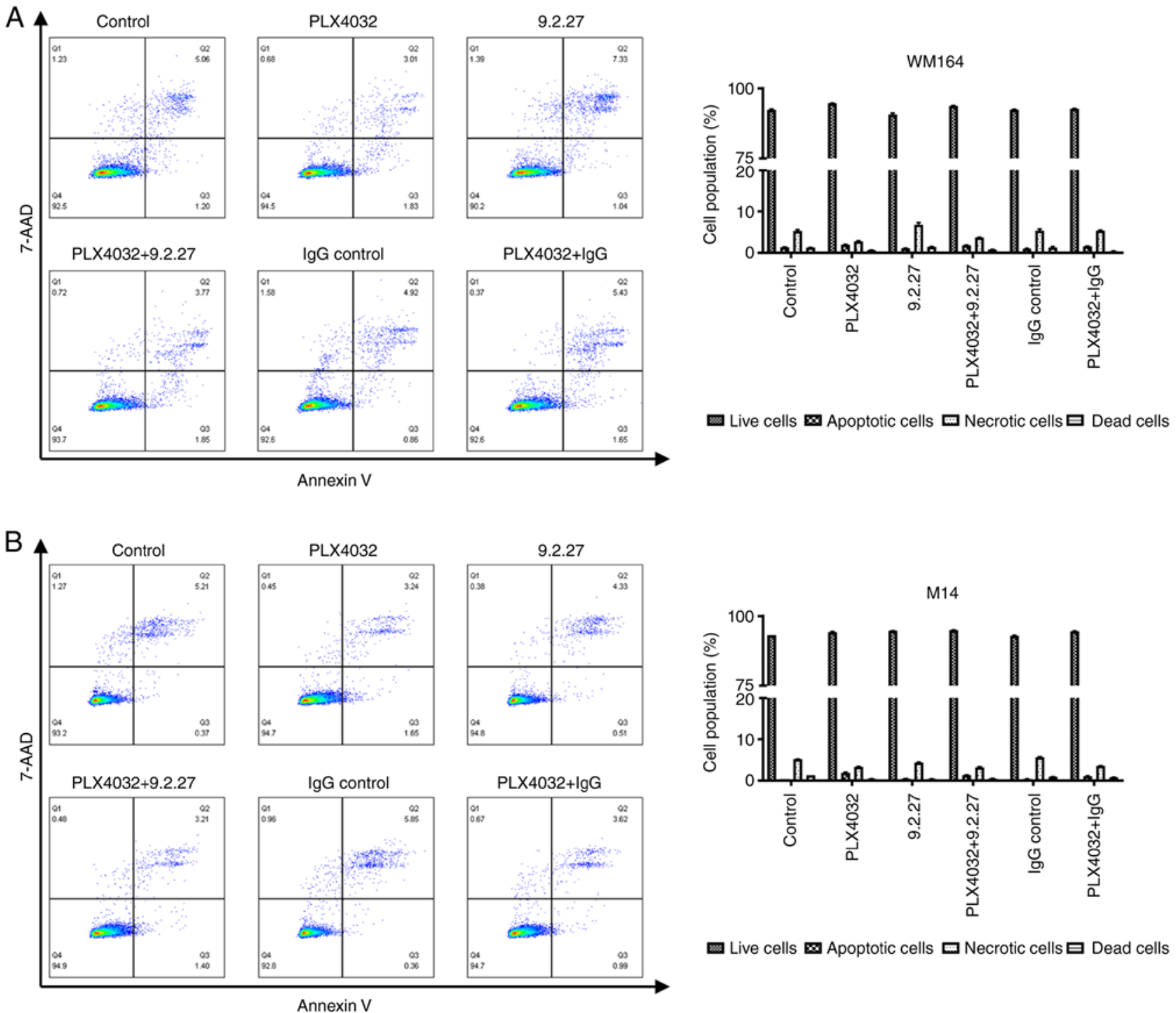

Figure 4. Detection of apoptosis of melanoma cells exposed for $72 \mathrm{~h}$ to PLX4032 and the CSPG4-specific 9.2.27 mAb alone or in combination. (A) Percentage of live, apoptotic, necrotic or dead CSPG4-positive WM164 cells, as well as (B) CSPG4-negative M14 cells upon treatments was evaluated using flow cytometry with Annexin V-CF Blue and 7-AAD staining. Results are shown as representative cytograms (left panels) and reported in bar graphs (right panels). Bars represent the mean \pm SD from triplicates of three independent experiments. Statistical analysis was carried out using one-way ANOVA with Tukey's multiple comparisons test. The accurate P-values are provided in Tables SI and SII. CSPG4, chondroitin sulfate proteoglycan 4; mAb, monoclonal antibody.

From these results, it can be concluded that the $9.2 .27 \mathrm{mAb}$ efficiently suppressed the CSPG4-mediated invasion of CSPG4-positive, but not CSPG4-negative cells and that this effect was comparable to the inhibitory effects of PLX4032.

Characterization of the apoptosis of melanoma cell lines. To gain insight into the potential mechanisms through which these specific treatments (PLX4032, CSPG4-specific mAb and the combination thereof) influenced the viability, clonogenicity and invasiveness of melanoma cells, the flow cytometric analysis of apoptosis was performed. Following exposure to specific treatments, the WM164 and M14 cells were subjected to Annexin $\mathrm{V}$ and 7-AAD staining in order to determine the proportions of viable cells (Annexin', 7-AAD'), early apoptotic (Annexin', 7-AAD), late apoptotic/necrotic (Annexin ${ }^{+}$, 7-AAD ${ }^{+}$), as well as dead cells (Annexin', 7-AAD ${ }^{+}$).

It was expected that the melanoma cells would exhibit early signs of apoptosis following exposure to the treatments at after $72 \mathrm{~h}$ if this process of programmed cell death was induced. Exposure to PLX4032, the CSPG4-specific 9.2.27 $\mathrm{mAb}$ or the combination thereof for $72 \mathrm{~h}$ did not induce the apoptosis of either the WM164 nor M14 cells (Fig. 4). Incubation of the WM164 cells with PLX4032 induced early apoptosis only in $1.96 \pm 0.12 \%$ of the cells, as compared with $1.32 \pm 0.14 \%$ of the control cells that were detected as apoptotic (Fig. 4A, right panel). Exposure of the WM164 cells to the CSPG4-specific $9.2 .27 \mathrm{mAb}$ increased the percentage of necrotic cells to $6.81 \pm 0.94 \%$, as compared with $5.11 \pm 0.38 \%$ of necrotic cells in the control; however, this effect was not statistically significant ( $\mathrm{P}=0.072$; Fig. $4 \mathrm{~A}$, right panel). Moreover, the increase in necrotic cells was not observed following treatment with PLX4032 plus the 9.2.27 mAb. Exposure of the M14 cells to all treatment variants resulted in $5.21 \pm 0.13 \%$ of cells that were apoptotic, necrotic or dead, while $94.6 \pm 0.26 \%$ of the treated cells were still detected as alive (Fig. 4B, right panel). 

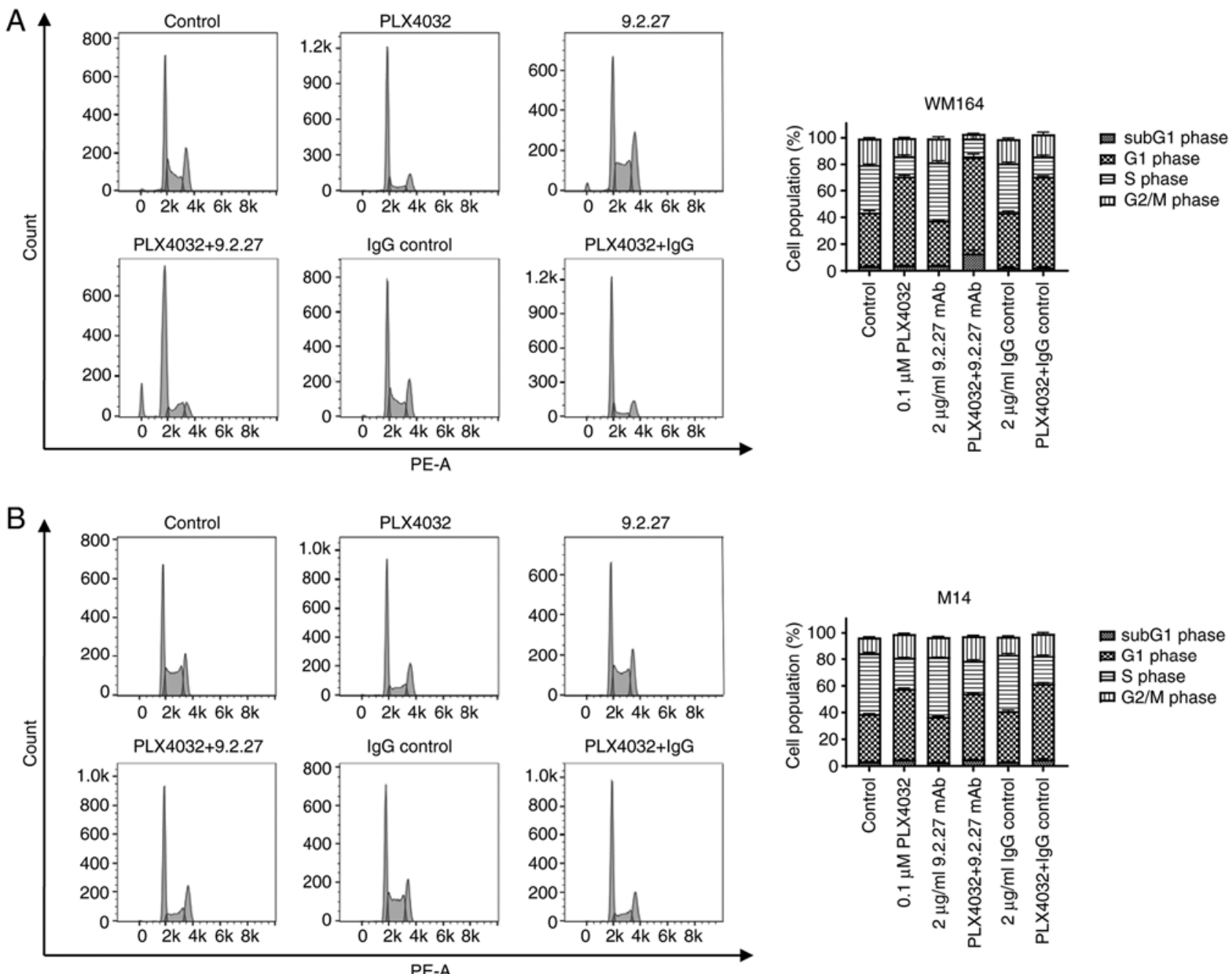

Figure 5. Cell cycle analysis of melanoma cells exposed for $72 \mathrm{~h}$ to PLX4032, the CSPG4-specific 9.2.27 mAb and the combination thereof. (A) CSPG4-positive WM164 cells and (B) CSPG4-negative M14 cells exposed to different treatments were analyzed for cell cycle distribution using flow cytometry with propidium iodide staining. Results are shown as representative histograms (left panels). The percentage of cells in different phases: subG1, G1, S and G2/M are reported in the bar graphs (right panels) and present the data of three individual experiments performed in triplicate. CSPG4, chondroitin sulfate proteoglycan 4; mAb, monoclonal antibody.

Taken together, these results indicated that the incubation of melanoma cell lines during these treatments for $72 \mathrm{~h}$ did not lead to the induction of apoptosis.

CSPG4-specific 9.2.27 mAb leads to WM164 cell cycle arrest in the S-phase. To determine whether the exposure of M14 and WM164 melanoma cells for $72 \mathrm{~h}$ to PLX4032, CSPG4-specific 9.2.27 $\mathrm{mAb}$ or their combination in turn affects the cell cycle, the treated cells were analyzed using flow cytometry after propidium iodide staining.

Incubation of the CSPG4-positive WM164 cells with the CSPG4-specific 9.2.27 mAb resulted in a significantly higher number of cells arrested in the $\mathrm{S}$ phase $(44.2 \pm 1.6 \%)$, as compared with the control $(35.9 \pm 0.96 \%)$ (Fig. 5A and Table SI). Moreover, following the combined treatment, a significantly increased accumulation of cells in the subG1 phase $(16.63 \pm 5.1 \%)$, combined with a decrease of cells in the G2/M phase $(3.96 \pm 0.12 \%)$ was observed, as compared with cell cycle distribution in the control $(3.44 \pm 0.66 \%$ of cells in the subG1 phase and $19.90 \pm 0.92 \%$ of cells in the G2/M phase) (Fig. 5A and Table SI). Exposure to PLX4032 led to a significant increase of cells in the G1 phase $(66.5 \pm 1.34 \%)$, as compared with the untreated cells $(40.2 \% \pm 2.04)$ (Fig. 5A and Table SI).

The cell cycle analysis of the CSPG4-negative M14 cell line revealed that the untreated control cells presented the following cell cycle distribution: The subG1 phase, $3.43 \pm 0.17 \%$; G1 phase, $35.6 \pm 0.21 \%$; S phase, $45.87 \pm 0.82 \%$; and $\mathrm{G} 2 / \mathrm{M}$ phase, $11.73 \pm 0.78 \%$ cells (Fig. 5B). Incubation with CSPG4-specific 9.2.27 mAb did not affect the cell cycle distribution of M14 cells (Fig. 5B). The combination of PLX4032 and 9.2.27 mAb resulted in similar cell cycle phases, as observed for PLX4032 alone (Fig. 5B). Upon exposure to PLX4032, a significant increase of M14 cells in the G1 phase was observed (52.9 $\pm 0.78 \%$ ) (Fig. 5B and Table SII).

To verify whether the CSPG4-specific 9.2.27 mAb affects CSPG4-positive WM164 cells in a concentration-dependent manner, the cells were exposed to increasing concentrations of the $\mathrm{mAb}(2-10 \mu \mathrm{g} / \mathrm{ml})$ and cell cycle analysis was performed. Indeed, higher antibody concentrations were associted with a higher percentage of cells arrested in the $S$ phase (Fig. S4). 
Taken together, these results indicate that the CSPG4-specific $\mathrm{mAb}$ can lead to cell cycle arrest in the $\mathrm{S}$ phase and that the combination with the BRAF inhibitor PLX4032 may lead to an increased cell death of CSPG4-postitive cells.

\section{Discussion}

Malignant melanoma is one of the most prevalent forms of fatal skin cancer with a continuous increasing incidence worldwide (37). Despite a significant improvement of treatment options owing to the introduction of BRAF and MEK inhibitors, a vast majority of patients with melanoma cannot fully benefit from therapy due to the intrinsic and acquired resistance to these drugs (22-24). mAbs constitute a rapidly expanding class of agents for the treatment of different cancer types, offering an alternative option to patients who have failed or progressed on a standard therapy (38). One approach is the use of mAbs that target the negative regulators of T-cell activation to yield increased anti-tumor immunity, including antibodies directed against programmed cell death-ligand 1 (PD-L1) and its receptor programmed cell death protein 1 (PD-1). These immune checkpoint inhibitor-based therapies have exhibited satisfactory clinical results in the treatment of patients with metastatic melanoma and other malignancies, such as lung cancer, colorectal cancer or renal cell carcinoma (38). The analysis of a phase 3 clinical trial revealed that the addition of the anti-PD-L1 antibody atezolizumab to targeted therapy with BRAF and MEK inhibitors significantly increased progression-free survival in patients with advanced melanoma (39). However, there are currently no clinically available antibodies that directly target membrane associated melanoma-specific proteins, such as cell-adhesion receptors. Some of the preclinical approaches focus on targeting CSPG4, since this proteoglycan is overexpressed on melanomas with only limited distribution on normal tissues and plays a central role in oncogenic pathways required for malignant progression and metastasis $(13,14)$.

The use of an appropriate mAb against CSPG4, as well as the validation of whether this specific anti-CSPG4 mAb can synergize with kinase inhibitors in order to enhance the initial response to the drug, may contribute to the design of more effective treatments against melanoma. The present study analyzed the antitumor effects of the CSPG4-specific mAb clone 9.2.27 alone and in combination with the commonly used selective BRAF inhibitor, PLX4032. To the best of our knowledge, this is the first study on the combination of these two agents on different melanoma cellular functions.

The results of the present study proved that exposure to PLX4032 efficiently inhibited the viability of BRAF V600E-mutant cells, both expressing (WM164) and not-expressing (M14) CSPG4 (Figs. 1 and S1). Studies employing the CSPG4-specific mAb clone 225.28 (25), as well as anti-CSPG4 polyclonal Abs (26) demonstrated that these antibodies reduced the viability of melanoma cells in vitro by $\sim 30 \%$. In the present study, the mAb clone 9.2.27 also decreased the viability of CSPG4-positive WM164 cells, whereas no reduction of the CSPG4-negative M14 cell line could be observed (Fig. 1 and S1). This result confirmed the specificity of the $9.2 .27 \mathrm{mAb}$ and proved that there was not even a minimal off-target effect on CSPG4-negative M14 cells. The extent of the decrease in viability following exposure to the 9.2.27 $\mathrm{mAb}$ was lower than that in studies focusing on $\mathrm{mAb}$ conjugated to radioisotopes or toxins $(17,18)$. However, the effect of the antibody alone on melanoma cell viability was not examined in these studies. Nevertheless, the CSPG4-specific 9.2.27 mAb significantly enhanced the effect of PLX4032 and reduced the viability of WM164 cells even after $24 \mathrm{~h}$ by an additional 19\% (Fig. 1A). This finding provided the rationale for further experiments described in the present study, analyzing whether the combination of a BRAF inhibitor with CSPG4-specific mAbs would be more effective in inhibiting melanoma cell survival and invasion.

CSPG4 is known to enhance cell survival through its involvement in promoting high levels of integrin-related signals and thus activating intracellular signaling cascades, particularly the FAK and PI3K/AKT pathways $(11,12)$. Indeed, incubation with the 9.2.27 mAb exerted a significant inhibitory effect on the colony-forming ability of CSPG4-positive melanoma cells, to the same extent as to treatment with PLX4032 alone (Fig. 2A). A combination of PLX4032 and 9.2.27 mAb, which theoretically should influence different pathways and result in a decreased capability of melanoma cells to form colonies, did not contribute to any additional inhibitory effect (Fig. 2A).

It was hypothesized speculate that the downregulation of CSPG4 expression in melanoma colonies may be involved in this observation. As recently demonstrated by the authors, exposure of CSPG4-positive melanoma cells to PLX4032 for up to 14 days led to gradually reduced levels of the CSPG4 protein and decreased levels of its mRNA (36). Therefore, the exposure of WM164 colonies to PLX4032 for a longer time period has probably led to a downregulation of CSPG4 expression and -as a consequence-to a lower binding of the CSPG4-specific mAb.

The progression of metastatic melanoma is a complex, multi-step process of molecular events that eventually results in an invasive phenotype. Since CSPG4 possesses the ability to coordinate several melanoma pathways, it is involved in tumorigenesis at multiple levels (3). Thus, the present study investigated the invasive properties of cells following exposure to treatments using 3D melanoma tumor spheroids.

Spheroids embedded in a collagen matrix reflect the in vivo tumor architecture and microenvironment, as they reconstruct the oxygen and nutrient gradient within the spheroid with central necrosis and a hypoxic zone; features that may influence the response to the treatment (30). The inhibitory effect of PLX4032 on the growth and invasion of 3D melanoma spheroids was successfully reflected in the regression of tumor growth in melanoma xenografts $(31,32)$. In line with these data, the present study demonstrated that PLX4032 significantly inhibited the invasion of M14 and WM164 spheroids (Fig. 3). Exposure to 9.2.27 mAb inhibited the invasion of CSPG4-positive spheroids to the same extent as PLX4032 (Fig. 3A and C). This result may be attributed to the suppression of the CSPG4-mediated invasion of cells, which involves the activation of MMP complexes on the cell surface and binding to ECM components, including collagen and fibronectin $(40,41)$.

The use of spheroids in this experiment allows us to hypothesize that this result could be projected to an in vivo situation. Indeed, Hsu et al (9) demonstrated that a 9.2.27 mAb 
immunotherapy inhibited the tumor growth of human sarcoma xenografts. In addition, it has been demonstrated showed that unconjugated 9.2.27 $\mathrm{mAb}$ is also able to suppress tumor growth in athymic mice to the same extent as with antibody conjugated to diphtheria toxin A chain (15). The combination of anti-CSPG4 antibodies with BRAF inhibitors has been studied to date only in two-dimensional cell culture assays $(25,26)$. The results presented herein indicated that 9.2.27 $\mathrm{mAb}$ did not enhance the inhibitory effect of PLX4032 on the invasiveness of CSPG4-positive spheroids (Fig. 3A and C). This may suggest that the combination would have a similar effect on tumor growth in vivo.

Hypoxia strongly influences the response to PLX432 treatment in melanoma cells which switch to a more invasive and aggressive phenotype (26). Therefore, therapeutic efforts have to take into account that the microenvironment of melanoma cells has an impact on tumor progression. Spheroids resemble the tumor hypoxic zone and CSPG4 expression has been shown to be upregulated both at the mRNA level and the protein level under hypoxic conditions (8). The 9.2.27 mAb significantly inhibited the invasion of CSPG4-positive spheroids, possibly overcoming the CSPG4 overexpression by hypoxic conditions.

Therefore, it would be of importance to test additional treatment variants before moving to in vivo studies with the 9.2.27 $\mathrm{mAb}$ and BRAF inhibitors. One approach could consist of first treating CSPG4-positive melanoma cells with the 9.2.27 mAb in order to restrict the CSPG4-dependendent growth, motility and invasiveness of tumor and then adding PLX4032. The intermittent dosing of this BRAF inhibitor alternating with CSPG4-specfic mAb could increase the duration of the initial response and delay or even prevent the development of resistance to the BRAF inhibitor.

The present study focused on investigating the underlying mechanisms of treatments on melanoma cells by discriminating live, early apoptotic and late apoptotic or necrotic cells along with assessing cell cycle distribution by flow cytometry. Exposure to PLX4032, the CSPG4-specific 9.2.27 mAb or the combination thereof for $72 \mathrm{~h}$ did not induce the apoptosis of either the M14 or WM164 cells (Fig. 4). Thus, it was suspected that changes in cell cycle distribution would be detected in cells exposed to treatments.

Indeed, exposure of both the M14 and WM164 cells to PLX4032 resulted in a significant increase in the number of cells in the G1 phase as compared with the control (Fig. 5). This is in line with the findings of another study analyzing the effects of PLX4032 on melanoma cell lines (42). Of note, the present study revealed that the incubation of CSPG4-positive cells with the CSPG4-specific 9.2.27 mAb resulted in a significantly higher number of cells arrested in the $S$ phase and that this effect was concentration-dependent (Figs. 5A and S2). The effect was specific since the incubation of the M14 cells with the anti-CSPG4 9.2.27 mAb did not influence the cell cycle distribution among these cells, while the combination of PLX4032 and the 9.2.27 mAb resulted in similar cell cycle phases, as observed with PLX4032 alone (Fig. 5B).

Relatively little is known about the mechanisms that control progression through the $\mathrm{S}$ phase in mammalian cells. Antibody treatment acts presumably as a CSPG4-dependent exogenous trigger that allows cells neither to progress in the cell cycle nor to retreat to the G1 status. Further investigation of molecular mediators of the $\mathrm{S}$ phase arrest in the context of
CSPG4 inhibition may shed light not only on the S phase arrest mechanisms, but also on as yet unidentified CSPG4 functions.

Moreover, following the combined treatment of WM164 cells, a significantly increased accumulation of cells in the subG1 phase, which may indicate cell death, combined with a decrease in the G2/M phase cells was observed (Fig. 5B). This result may explain the decreased viability of WM164 cells exposed to PLX4032 and the 9.2.27 mAb (Fig. 1A).

In conclusion, the findings of the present study indicate that the CSPG4-specific 9.2.27 mAb exerted an anti-clonogenic and anti-invasive effect on CSPG4-expressing melanoma cells. In addition, antibody treatment led to cell cycle arrest in the $\mathrm{S}$ phase. Albeit the combination of the 9.2.27 mAb with PLX4032 did not exert any additional effect on the colony formation ability and invasiveness of CSPG4-positive cells, the combined treatment may lead to increased cell death. The outcomes of the present study provide the basis for further investigations and emphasize the need for new considerations when designing studies involving the combination of CSPG4-specific mAbs with kinase inhibitors for the treatment of CSPG4-positive tumors.

\section{Acknowledgements}

The authors would like to thank Dr Claudia Kitzmüller (Department of Pathophysiology and Allergy Research, Center for Pathophysiology, Infectiology and Immunology, Medical University of Vienna, Austria) for providing technical assistance with the flow cytometry experiments and Dr Helmut Schaider (Dermatology Research Centre, The University of Queensland Diamantina Institute, Translational Research Institute, The University of Queensland, Brisbane, Australia) for providing the WM164 melanoma cell line. The authors also wish to acknowledge the NÖ Landesgesundheitsagentur, legal entity of University Hospitals in Lower Austria, for providing the organizational framework for conducting this research.

\section{Funding}

The present study was funded by the NÖ Forschungs-und Bildungsges.m.b.H. (NFB), grant no. LSC15-007. The authors also acknowledge the support by the Open Access Publishing Fund of the Karl Landsteiner University of Health Sciences, Krems, Austria.

\section{Availability of data and materials}

The datasets used and/or analyzed during the current study are available from the corresponding author upon reasonable request.

\section{Authors' contributions}

$\mathrm{KU}$ and $\mathrm{CH}$ conceived and designed the study, and analyzed and interpreted the data. MS, TK, MP and HB participated in designing the study and in analyzing the data. KU and MS performed all the experiments. $\mathrm{CH}$ and $\mathrm{HB}$ confirm the authenticity of all the raw data. $\mathrm{KU}, \mathrm{CH}$ and $\mathrm{HB}$ wrote the manuscript. All authors have read and revised the manuscript, and approved the final version. 


\section{Ethics approval and consent to participate}

Not applicable.

\section{Patient consent for publication}

Not applicable.

\section{Competing interests}

MP is a clinical investigator for Bayer, BMS, Lilly and Roche; MP received speaker honoraria from Bayer, BMS, Eisai, Lilly, and MSD; MP is a consultant for Bayer, BMS, Ipsen, Eisai, Lilly, MSD, and Roche outside the presented work; MP received travel support from Bayer and BMS. KU, MS, TK, $\mathrm{HB}$ and $\mathrm{CH}$ declare that they have no competing interests.

\section{Authors' information}

The ORCID IDs of all the authors are as follows: KU, 0000-0003-0093-6047; MS, 0000-0003-0842-6578; TK, 0000-0002-9641-0244; MP, 0000-0002-7260-532X; $\mathrm{CH}$, 0000-0003-3745-1414; and HB, 0000-0003-2022-8689.

\section{References}

1. Wilson BS, Imai K, Natali PG and Ferrone S: Distribution and molecular characterization of a cell-surface and a cytoplasmic antigen detectable in human melanoma cells with monoclonal antibodies. Int J Cancer 28: 293-300, 1981.

2. Campoli MR, Chang CC, Kageshita T, Wang X, McCarthy JB and Ferrone S: Human high molecular weight-melanoma-associated antigen (HMW-MAA): A melanoma cell surface chondroitin sulfate proteoglycan (MSCP) with biological and clinical significance. Crit Rev Immunol 24: 267-296, 2004.

3. Campoli M, Ferrone S and Wang X: Functional and clinical relevance of chondroitin sulfate proteoglycan 4. Adv Cancer Res 109: 73-121, 2010.

4. Fenton M, Whiteside TL,Ferrone $S$ and Boyiadzis M: Chondroitin sulfate proteoglycan-4 (CSPG4)-specific monoclonal antibody 225.28 in detection of acute myeloid leukemia blasts. Oncol Res 22: 117-121, 2015.

5. Warta R, Herold-Mende C, Chaisaingmongkol J, Popanda O, Mock A, Mogler C, Osswald F, Herpel E, Küstner S Eckstein $\mathrm{V}$, et al: Reduced promoter methylation and increased expression of CSPG4 negatively influences survival of HNSCC patients. Int J Cancer 135: 2727-2734, 2014.

6. Wang X, Osada T, Wang Y, Yu L, Sakakura K, Katayama A, McCarthy JB, Brufsky A, Chivukula M, Khoury T, et al: CSPG4 protein as a new target for the antibody-based immunotherapy of triple-negative breast cancer. J Natl Cancer Inst 102: 1496-1512, 2010

7. Svendsen A, Verhoeff JJ, Immervoll H, Brøgger JC, Kmiecik J, Poli A, Netland IA, Prestegarden L, Planagumà J, Torsvik A, et al: Expression of the progenitor marker NG2/CSPG4 predicts poor survival and resistance to ionising radiation in glioblastoma. Acta Neuropathol 122: 495-510, 2011.

8. Keleg S, Titov A, Heller A, Giese T, Tjaden C, Ahmad SS, Gaida MM, Bauer AS, Werner J and Giese NA: Chondroitin sulfate proteoglycan CSPG4 as a novel hypoxia-sensitive marker in pancreatic tumors. PLoS One 9: e100178, 2014.

9. Hsu SC, Nadesan P, Puviindran V, Stallcup WB, Kirsch DG and Alman BA: Effects of chondroitin sulfate proteoglycan 4 (NG2/CSPG4) on soft-tissue sarcoma growth depend on tumor developmental stage. J Biol Chem 293: 2466-2475, 2018.

10. Rivera Z, Ferrone S, Wang X, Jube S, Yang H, Pass HI, Kanodia S, Gaudino G and Carbone M: CSPG4 as a target of antibody-based immunotherapy for malignant mesothelioma. Clin Cancer Res 18: 5352-5363, 2012.

11. Price MA, Colvin Wanshura LE, Yang J, Carlson J, Xiang B, Li G, Ferrone S, Dudek AZ, Turley EA and McCarthy JB: CSPG4, a potential therapeutic target, facilitates malignant progression of melanoma. Pigment Cell Melanoma Res 24: 1148-1157, 2011.
12. Yang J, Price MA, Neudauer CL, Wilson C, Ferrone S, Xia H, Iida J, Simpson MA and McCarthy JB: Melanoma chondroitin sulfate proteoglycan enhances FAK and ERK activation by distinct mechanisms. J Cell Biol 165: 881-891, 2004.

13. Ilieva KM, Cheung A, Mele S, Chiaruttini G, Crescioli S, Griffin M, Nakamura M, Spicer JF, Tsoka S, Lacy KE, et al: Chondroitin sulfate proteoglycan 4 and its potential as an antibody immunotherapy target across different tumor types. Front Immunol 8: 1911, 2017.

14. Rolih V, Barutello G, Iussich S, De Maria R, Quaglino E, Buracco P, Cavallo F and Riccardo F: CSPG4: A prototype oncoantigen for translational immunotherapy studies. J Transl Med 15: 151, 2017.

15. Bumol TF, Wang QC, Reisfeld RA and Kaplan NO: Monoclonal antibody and an antibody-toxin conjugate to a cell surface proteoglycan of melanoma cells suppress in vivo tumor growth. Proc Natl Acad Sci USA 80: 529-533, 1983.

16. Jordaan S, Chetty S, Mungra N, Koopmans I, van Bommel PE, Helfrich W and Barth S: CSPG4: A target for selective delivery of human cytolytic fusion proteins and TRAIL. Biomedicines 5: 37, 2017.

17. Abbas Rizvi SM, Sarkar S, Goozee G and Allen BJ: Radioimmunoconjugates for targeted alpha therapy of malignant melanoma. Melanoma Res 10: 281-289, 2000.

18. Risberg K, Fodstad O and Andersson Y: The melanoma specific 9.2.27PE immunotoxin efficiently kills melanoma cells in vitro. Int J Cancer 125: 23-33, 2009.

19. de Bruyn M, Rybczynska AA, Wei Y, Schwenkert M, Fey GH, Dierckx RA, van Waarde A, Helfrich W and Bremer E: Melanoma-associated Chondroitin Sulfate Proteoglycan (MCSP)-targeted delivery of soluble TRAIL potently inhibits melanoma outgrowth in vitro and in vivo. Mol Cancer 9: 301, 2010.

20. Amoury M, Mladenov R, Nachreiner T, Pham AT, Hristodorov D, Di Fiore S, Helfrich W, Pardo A, Fey G, Schwenkert M, et al: A novel approach for targeted elimination of CSPG4-positive triple-negative breast cancer cells using a MAP tau-based fusion protein. Int J Cancer 139: 916-927, 2016.

21. Poli A, Wang J, Domingues O, Planagumà J, Yan T, Rygh CB, Skaftnesmo KO, Thorsen F, McCormack E, Hentges F, et al: Targeting glioblastoma with NK cells and $\mathrm{mAb}$ against NG2/CSPG4 prolongs animal survival. Oncotarget 4: 1527-1546, 2013.

22. Chapman PB, Hauschild A, Robert C, Haanen JB, Ascierto P, Larkin J, Dummer R, Garbe C, Testori A, Maio M, et al: Improved survival with vemurafenib in melanoma with BRAF V600E mutation. N Engl J Med 364: 2507-2516, 2011.

23. Proietti I, Skroza N, Michelini S, Mambrin A, Balduzzi V, Bernardini N, Marchesiello A, Tolino E, Volpe S, Maddalena P, et al: BRAF Inhibitors: Molecular targeting and immunomodulatory actions. Cancers (Basel) 12: 1823, 2020.

24. Patel H, Yacoub N, Mishra R, White A, Long Y, Alanazi S and Garrett JT: Current advances in the treatment of BRAF-mutant melanoma. Cancers (Basel) 12: 482, 2020.

25. Yu L, Favoino E, Wang Y, Ma Y, Deng X and Wang X: The CSPG4-specific monoclonal antibody enhances and prolongs the effects of the BRAF inhibitor in melanoma cells. Immunol Res 50: 294-302, 2011.

26. Pucciarelli $\mathrm{D}$, Lengger N, Takacova M, Csaderova L, Bartosova M, Breiteneder H, Pastorekova S and Hafner C: Anti-chondroitin sulfate proteoglycan 4-specific antibodies modify the effects of vemurafenib on melanoma cells differentially in normoxia and hypoxia. Int J Oncol 47: 81-90, 2015.

27. Costa EC, Moreira AF, de Melo-Diogo D, Gaspar VM, Carvalho MP and Correia IJ: 3D tumor spheroids: An overview on the tools and techniques used for their analysis. Biotechnol Adv 34: 1427-1441, 2016.

28. Bialkowska K, Komorowski P, Bryszewska M and Milowska K: Spheroids as a type of three-dimensional cell cultures-examples of methods of preparation and the most important application. Int J Mol Sci 21: 6225, 2020.

29. Pampaloni F, Reynaud EG and Stelzer EH: The third dimension bridges the gap between cell culture and live tissue. Nat Rev Mol Cell Biol 8: 839-845, 2007.

30. Beaumont KA, Mohana-Kumaran N and Haass NK: Modeling melanoma in vitro and in vivo. Healthcare (Basel) 2: 27-46, 2013.

31. Tsai J, Lee JT, Wang W, Zhang J, Cho H, Mamo S, Bremer R, Gillette S, Kong J, Haass NK, et al: Discovery of a selective inhibitor of oncogenic B-Raf kinase with potent antimelanoma activity. Proc Natl Acad Sci USA 105: 3041-3046, 2008. 
32. Lee JT, Li L, Brafford PA, van den Eijnden M, Halloran MB Sproesser K, Haass NK, Smalley KS, Tsai J, Bollag G and Herlyn M: PLX4032, a potent inhibitor of the B-Raf V600E oncogene, selectively inhibits V600E-positive melanomas. Pigment Cell Melanoma Res 23: 820-827, 2010.

33. Smalley KS, Haass NK, Brafford PA, Lioni M, Flaherty KT and Herlyn M: Multiple signaling pathways must be targeted to overcome drug resistance in cell lines derived from melanoma metastases. Mol Cancer Ther 5: 1136-1144, 2006.

34. Haass NK, Sproesser K, Nguyen TK, Contractor R, Medina CA, Nathanson KL, Herlyn M and Smalley KS: The mitogen-activated protein/extracellular signal-regulated kinase kinase inhibitor AZD6244 (ARRY-142886) induces growth arrest in melanoma cells and tumor regression when combined with docetaxel. Clin Cancer Res 14: 230-239, 2008.

35. Hafner C, Breiteneder H, Ferrone S, Thallinger C, Wagner S, Schmidt WM, Jasinska J, Kundi M, Wolff K, Zielinski CC, et al: Suppression of human melanoma tumor growth in SCID mice by a human high molecular weight-melanoma associated antigen (HMW-MAA) specific monoclonal antibody. Int J Cancer 114: 426-432, 2005.

36. Uranowska K, Kalic T, Valtsanidis V, Kitzwogerer M, Breiteneder $\mathrm{H}$ and Hafner C: Expression of chondroitin sulfate proteoglycan 4 (CSPG4) in melanoma cells is downregulated upon inhibition of BRAF. Oncol Rep 45: 14, 2021.

37. Schadendorf D, van Akkooi ACJ, Berking C, Griewank KG Gutzmer R, Hauschild A, Stang A, Roesch A and Ugurel S: Melanoma. Lancet 392: 971-984, 2018.
38. Kimiz-Gebologlu I, Gulce-Iz S and Biray-Avci C: Monoclonal antibodies in cancer immunotherapy. Mol Biol Rep 45: 2935-2940, 2018.

39. Gutzmer R, Stroyakovskiy D, Gogas H, Robert C, Lewis K, Protsenko S, Pereira RP, Eigentler T, Rutkowski P, Demidov L, et al: Atezolizumab, vemurafenib, and cobimetinib as first-line treatment for unresectable advanced BRAF ${ }^{\mathrm{V} 600}$ mutation-positive melanoma (IMspire150): Primary analysis of the randomised, double-blind, placebo-controlled, phase 3 trial. Lancet 395: 1835-1844, 2020.

40. Iida J, Wilhelmson KL, Ng J, Lee P, Morrison C, Tam E, Overall CM and McCarthy JB: Cell surface chondroitin sulfate glycosaminoglycan in melanoma: Role in the activation of pro-MMP-2 (pro-gelatinase A). Biochem J 403: 553-563, 2007.

41. Tang F, Lord MS, Stallcup WB and Whitelock JM: Cell surface chondroitin sulphate proteoglycan 4 (CSPG4) binds to the basement membrane heparan sulphate proteoglycan, perlecan, and is involved in cell adhesion. J Biochem 163: 399-412, 2018.

42. Sondergaard JN, Nazarian R, Wang Q, Guo D, Hsueh T, Mok S, Sazegar H, MacConaill LE, Barretina JG, Kehoe SM, et al: Differential sensitivity of melanoma cell lines with BRAFV600E mutation to the specific Raf inhibitor PLX4032. J Transl Med 8: 39, 2010.

This work is licensed under a Creative Commons Attribution 4.0 International (CC BY 4.0) License. 